\title{
Differentiation as a basis for explaining customer satisfaction across industries
}

\author{
Claes Fornell, Michael D. Johnson * \\ Unicersity of Michigan, School of Business Administration, Ann Arbor, MI 48109-1234, USA
}

Received September 5, 1991; accepted April 14, 1993

The paper uses the differentiation of offerings as a basis for explaining differences in aggregate, industry level customer satisfaction in the annual Swedish Customer Satisfaction Barometer. The results reveal that differentiated industries have higher aggregate levels of perceived performance and subsequent customer satisfaction, and that a large portion of variance in customer satisfaction across industries can be explained by the impact of differentiation (via perceived performance). These findings suggest that it is indeed possible to make meaningful comparisons of customer satisfaction across different industries.

\section{Introduction}

Sweden was the first country to develop a single, national index of customer satisfaction as a new measure of economic output (Fornell, 1992). Germany followed suit last year and the United States is expected to announce the results of its American Customer Satisfaction Index in 1994. The Swedish Customer Satisfaction Barometer (CSB) tracks customer evaluations of product and service performance and satisfaction for a large number of companies in over thirty industries. The issue of this paper is just what aggregate, industry level differences in satisfaction mean. Does a satisfaction index score of 78 for automobiles versus 65 for postal service reflect an underlying difference in the degree to which these industries satisfy customer needs? If so, understanding the base level of satisfaction in an industry is critical when interpreting satisfaction measures for the

\footnotetext{
* Corresponding author. Tel.: (313) 764-1259.
}

Acknowledgment: The authors thank two anonymous reviewers for their comments and gratefully acknowledge the financial support of the Swedish Post Office. 
purpose of business strategy, or government intervention. Our benchmarks for judging satisfaction with products, services, and monopolies may be very different.

The goal of this research is to examine whether the industry level differences in the Swedish CSB are, in a sense, 'meaningful'. We use the concept of differentiation, or the existence of predictably different competitors in an industry, as a basis for explaining these differences in satisfaction. The research also develops a method for operationalizing the level of differentiation across industries. Overall we predict that aggregate satisfaction should increase with the degree of differentiation. In more differentiated industries, offerings are more likely to meet the particular needs of different customers. This should increase aggregate perceptions of product or service performance and subsequent aggregate satisfaction.

Although this prediction is consistent with basic economic and marketing principles, it has yet to be shown to drive performance and satisfaction differences at the industry level. There is a strong belief among some researchers that industry level satisfaction measures will not reveal any meaningful differences (Hunt, 1988; Ölander, 1988). We report on an empirical analysis of satisfaction levels across twentytwo industries over a four-year period (1989-1992). The results suggest that more differentiated industries are systematically higher in perceived performance and subsequent satisfaction. The results also suggest that monopolies have used these industry level benchmarks to improve their customer satisfaction in the face of pending competition.

\section{Industry level satisfaction}

Three questions are central to our examination of industry level differences in satisfaction. First, what are the antecedents of satisfaction at this level? Second, how should satisfaction be measured to provide meaningful industry level differences? Third, what drives these differences?

\subsection{The antecedents of industry level satisfaction}

Research on customer satisfaction has, until recently, focused primarily on individuals. This research supports a number of important 
determinants of individual level satisfaction, including perceived performance, expectations, and disconfirmation of expectations (for a review see $\mathrm{Yi}, 1991$ ). The principal determinant of satisfaction in much of this research has been disconfirmation, or the degree to which perceived performance exceeds or fails to realize expectations (see, e.g., Anderson, 1973; Oliver, 1977, 1980; Westbrook and Reilly, 1983). The disconfirmation model predicts that, while satisfaction should increase with performance, it should decrease with expectations. As expectations rise, so should negative disconfirmation.

However, the disconfirmation model should not hold in the context of aggregate, industry level satisfaction. The disconfirmation model requires that performance and expectations be relatively independent. While this may be true for some individuals, it should not describe entire industries where aggregate expectations are relatively accurate and consistent with perceived performance (Muth, 1961; Van Raaij, 1989). Thus we expect that the individual differences that drive phenomena such as disconfirmation wash out in the aggregate. This argument parallels that of Katona $(1975,1980)$, who argued that individual differences in optimism and pessimism wash out such that aggregate expectations are more important in predicting aggregate economic conditions.

This suggests a parsimonious model in which customer perceptions of product or service performance and their expectations regarding performance are the two primary antecedents of industry level satisfaction (Johnson and Fornell, 1991). Any exogenous factor, such as differentiation, should affect satisfaction via these primary antecedents. Aggregate perceptions of performance (i.e., perceived benefits less costs) should have a positive effect on industry level satisfaction. That is, industry level satisfaction should increase with the degree to which the products or services in that industry provide net benefits that customers value (Fornell, 1992; Westbrook and Reilly, 1983).

Although expectations and perceived performance should covary in the aggregate, expectations should also have some positive effect on satisfaction. Both Van Raaij (1989) and Schelling (1978) argue that aggregate expectations are somewhat 'self-fulfilling'. That is, because performance expectations embody all past performance information, aggregate satisfaction may be anchored in the vicinity of the expectations. Thus, as aggregate expectations increase, we expect some direct 
increase in aggregate satisfaction over and above the larger effects of performance on satisfaction. Katona $(1980,1975)$ demonstrated a similar type of effect in his research on the index of consumer sentiment. He argued and showed that aggregate economic expectations both predict and contribute to subsequent economic conditions.

This particular characterization of customer satisfaction is designed specifically with aggregate, industry level expectations and perceptions in mind. Our model and study do not necessarily describe the perceptions or behavior of individual consumers. At the same time, our research focuses on an area of customer satisfaction research that has been neglected. 'This area is particularly relevant for firms or industries whose competition crosses industry boundaries.

\subsection{Measuring satisfaction differences}

There is a debate as to whether satisfaction can be measured and meaningfully compared across industries. According to Pfaff (1977), customers are the best judges of their own experiences. However, Ölander (1977a, 1977b, 1988) and Hunt (1988) argue that aggregate measures of satisfaction (or subjective well-being) are inherently problematic and will not reveal meaningful industry level differences. Specifically, Ölander points out that customers may use different yardsticks to judge satisfaction, differ in their knowledge base, adapt to given performance levels, fail to express true dissatisfaction, or strategically express false dissatisfaction. Elster and Roemer (1991) suggest that the most important of these is the so-called 'happy slave' or 'sour grapes' problem; because customers adapt to the offerings in an industry, and some may adapt more easily than others, it may be difficult to make comparisons on the basis of aggregate satisfaction.

The counter argument is simply that, if the observed differences in satisfaction can be explained by some underlying difference among the industries, then the satisfaction differences are meaningful. That is, is there a logical or theoretical basis for expecting a difference among industries which, in turn, accounts for empirically observed differences in satisfaction? If so, then it makes sense to compare customer satisfaction across industries.

When examining these differences, it is important to recognize that satisfaction is an inherently abstract construct. It describes a customer's total consumption experience (Johnson and Fornell, 1991). 
Thus satisfaction, like utility, can not be equated with or measured directly by any one observable variable (Simon, 1974). Yet it can be measured indirectly as a latent variable using fallible proxies in a multiple indicators approach. Similar to the recent 'cardinalist' approaches to welfare measurement (Jorgenson, 1990; Tinbergen, 1991), the question is not whether satisfaction can be measured and compared, but how to interpret and explain any observed differences (Sen, 1979).

\subsection{Differentiation and industry satisfaction}

Although previous studies have documented differences in customer satisfaction across industries (Andreasen and Best, 1977; Pfaff, 1977; Wikström, 1983), it is unclear what drives these differences. We argue that one logical basis for explaining differences in aggregate level perceived performance, expectations, and satisfaction is the level of differentiation in an industry. In our context, differentiation refers to the existence of predictably different offerings. Differentiated industries recognize that buyers differ in their preferences and they develop products and services accordingly. They offer a variety of product or service offerings to meet the needs and wants of a heterogeneous population of customers (Grönroos, 1983). This leads to the basic proposition that differentiated industries should provide higher aggregate levels of perceived performance and, as a result, higher levels of aggregate satisfaction.

Empirically, operationalizing the concept of differentiation is similar to operationalizing satisfaction; it is difficult to equate differentiation with any single concrete measure or proxy. But one can use different measures of differentiation to operationalize the construct more indirectly as a latent variable. We suggest three different measures of differentiation here: the number of major competitors in an industry, the ease with which customers are able to evaluate product or service differences, and the product versus service orientation of the industry.

The first measure is the concentration or number of major competitors in an industry $\left(D_{1}\right)$. The greater the number or variety of options available, the more likely an option exists that meets the specific needs of any given customer. The companies included in the CSB from each industry were selected to account for approximately $70 \%$ of 
combined sales in the industry. Thus the number of firms included in the index from each industry serves as a reasonable proxy for concentration. Note that this is very different from previous arguments relating concentration to satisfaction (Fornell and Robinson, 1983). One such argument is that industries with high levels of concentration are less competitive, which results in lower quality products and more dissatisfied customers. Alternatively, concentration may reflect competitive efficiency, which could increase satisfaction. However, we do not focus on concentration or monopoly power per se. Rather, we simply argue that our concentration measure contains information regarding the existence of predictably different offerings. When combined with other measures, it can be used to operationalize the differentiation among offerings in an industry.

Our second measure of differentiation is the customers' aggregate perception of how easy it is to judge quality differences in an industry $\left(D_{2}\right)$. This measure draws directly on Howard's $(1977,1989)$ model of buyer behavior and more indirectly on signal detection theory in psychology (Lachman et al., 1979). According to Howard, distinctively different offerings are easier for consumers to judge. People are more confident evaluating differentiated offerings than they are evaluating similar offerings. In the CSB, customers are asked explicitly to evaluate how easy versus how difficult it is to evaluate quality differences in the industry. More differentiated offerings should rate higher on this measure. This assumes, of course, that there are no large differences in customer experience across the industries. If buyers in one industry have considerable experience judging options while those in another industry do not, then the measure might simply reveal differences in experience. However, as described shortly, all of the customers interviewed for the CSB were screened to include only those with experience in the category. Thus the 'ease of evaluation' measure should primarily reflect differences in the offerings rather than the customers.

The third measure is the product versus service orientation of the industries $\left(D_{3}\right)$. To be differentiated, a firm must be able to tailor its offering to conform to a particular customer's or market segment's needs. Products conform to specifications largely through their physical means of production. In contrast, services must conform to specifications through a production process that involves the human and nonhuman resources of the firm as well as the customers themselves. 


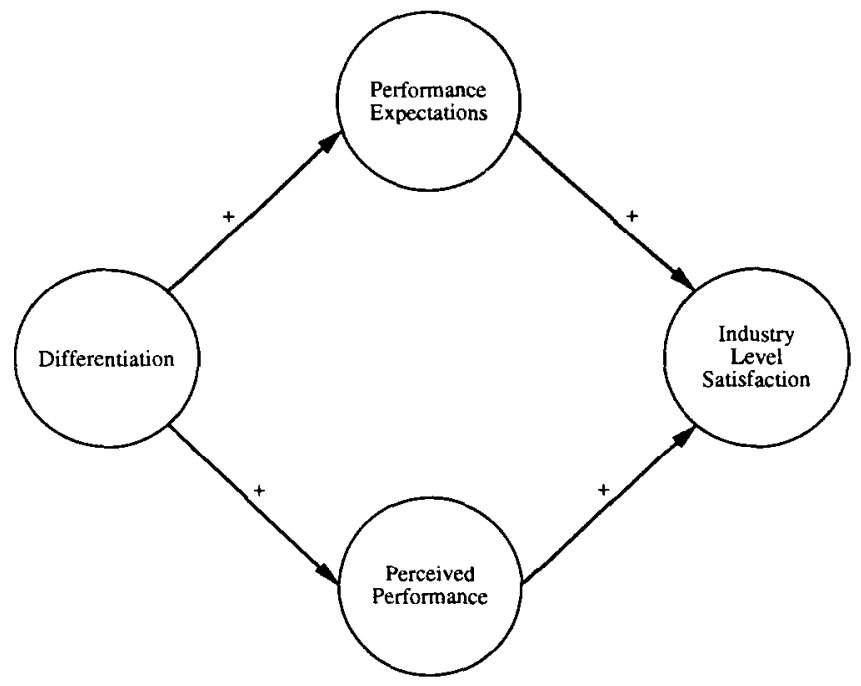

Fig. 1. Differentiation and industry satisfaction.

This creates greater uncertainty, on average, in the production of services when compared to products (Grönroos, 1983; Zeithaml et al., 1988). Because product oriented industries are inherently more capable of producing predictably different options, they should be more differentiated, on average, than service oriented industries.

Overall we expect the following. Differentiation should increase aggregate perceptions of performance which, in turn, should increase aggregate industry satisfaction. Because aggregate expectations are relatively accurate, they should mirror or covary with performance perceptions (Muth, 1961). Following Schelling (1978) and Van Raaij (1989), aggregate expectations should have some direct positive effect on satisfaction. These propositions are incorporated into Fig. 1. Also included in Fig. 1 is a direct positive effect of differentiation on expectations. Customers may have intuitive theories of marketers' actions (Wright, 1986) such that they expect more from more differentiated industries. This relationship is also consistent with Johnson and Fornell's (1991) argument that both expectations and perceived performance mediate industry-level satisfaction differences. 
It is important to note that the monopolies in the Swedish CSB were a major driving force in its creation. As privatization sweeps across Europe, these industries may lose their monopoly status in Sweden and face a significant increase in competition in the near future. Thus the monopolies are particularly interested in the industry level CSB indices. They provide competitive benchmarks for quality improvement that did not previously exist. Indeed, there is much that monopolies can do to attain higher customer satisfaction in a relatively short period of time. There is only one organization involved; the risk of some major initiative failing is minimal as there are, as yet, no direct competitors who would benefit and absorb market share. In the long run, of course, the monopolies must increase satisfaction to retain customers as competition increases. Our analysis will examine whether there are any trends in customer satisfaction for monopolies when compared to more competitive product and service industries.

\section{Empirical test}

Our propositions were tested using data from the Swedish CSB (Fornell, 1992). The index is based on ratings of customer satisfaction from representative customers in each of 28 industries for 1989 and 32 industries for 1990-1992. Again, the companies representing an industry account for approximately $70 \%$ of combined industry sales. For those firms which sell multiple products, the index focuses on the product or service with the highest sales (in kronor) to represent the company. For example, Volvo's ratings are based on its 700 series automobile, the Post Office's ratings are based on its letter and parcel delivery, and the Police's ratings are based on the handling of stolen car reports. Thus, even though some of the industries classified as monopolies in our study have several offerings, we focus on a particular offering on which they indeed have a monopoly.

Fach year approximately 100,000 respondents are contacted by telephone on a random basis. These respondents are screened to obtain a sample of customers who have experience with one of the products or services in the index. The resulting annual sample of approximately 25,000 respondents are then subjected to an eightminute telephone interview. With some exceptions (food products and television broadcasting), each respondent is asked about a single 
product or service. The annual sample sizes range from 250 for some monopolies to more than 4000 for some fragmented markets. The sampling error for the CSB ranges from $1.5 \%$ to $0.6 \%$ at the $95 \%$ level.

The respondents are asked a variety of questions to measure their expectations, perceptions of performance, and level of satisfaction. Expectations are measured by how well the customer expected the product or service to perform. The survey includes three different measures of satisfaction, overall satisfaction, confirmation of expectations, and distance from the customer's hypothetical ideal product or service in the industry. There are two measures of perceived performance (i.e., perceived benefits less costs), a rating of how well the product or service has performed given how much the customer paid and a rating of how much the customer paid given how well the product has performed. These measures are used to construct indices of customer expectations, perceived performance, and customer satisfaction each year for every industry (mean satisfaction scores are on a 0 to 100 scale). As these indices are more direct measures of the constructs involved (Johnson and Fornell, 1991), they are used here to test the conceptual model in Fig. 1. In order to utilize all four years of data, index measures from 1989 through 1992 are used as multiple indicators for expectations ( $E_{1}$ through $E_{4}$ ), performance ( $P_{1}$ through $\left.P_{4}\right)$, and satisfaction $\left(S_{1}\right.$ through $\left.S_{4}\right)$.

A total of twenty-two different industries were used to estimate the model. Following Fornell's (1992) classifications, these included eight durable and nondurable product manufacturers or retailers (automobiles, mainframe computers, personal computers, gas stations, supermarkets, clothing stores, department stores, and furniture stores) and fourteen service industries. The service industries include both competitive services (business banking, public banking, charter travel, business insurance, auto insurance, life insurance, airlines, and television broadcasting) and service monopolies (police department, business post, public post, railroads, business telephone service, and personal telephone service). Our third differentiation measure, $D_{3}$, is simply this two-level categorization of the industries according to their product versus service orientation. As described earlier, our other two reflective measures of differentiation are the number of firms included from the industry $\left(D_{1}\right)$ and the customers' ease of evaluating quality differences $\left(D_{2}\right)$. Not included in our analysis were (1) very 
frequently purchased food products for which expectations measures were not collected, and (2) those industries not included in the initial 1989 index.

\subsection{Analysis and results}

The model in Fig. 1 was estimated using the measures outlined above to test the propositions. Given the nature of the model, the multiple indicators and constructs, and sample size involved (22 industrics), the model was estimated using PLS (Wold, 1982, 1989). The recursive model estimation included direct effects of differentiation on expectations and perceived performance, and the effects of expectations and perceived performance on customer satisfaction. The covariance between expectations and performance was examined using their latent variable correlation.

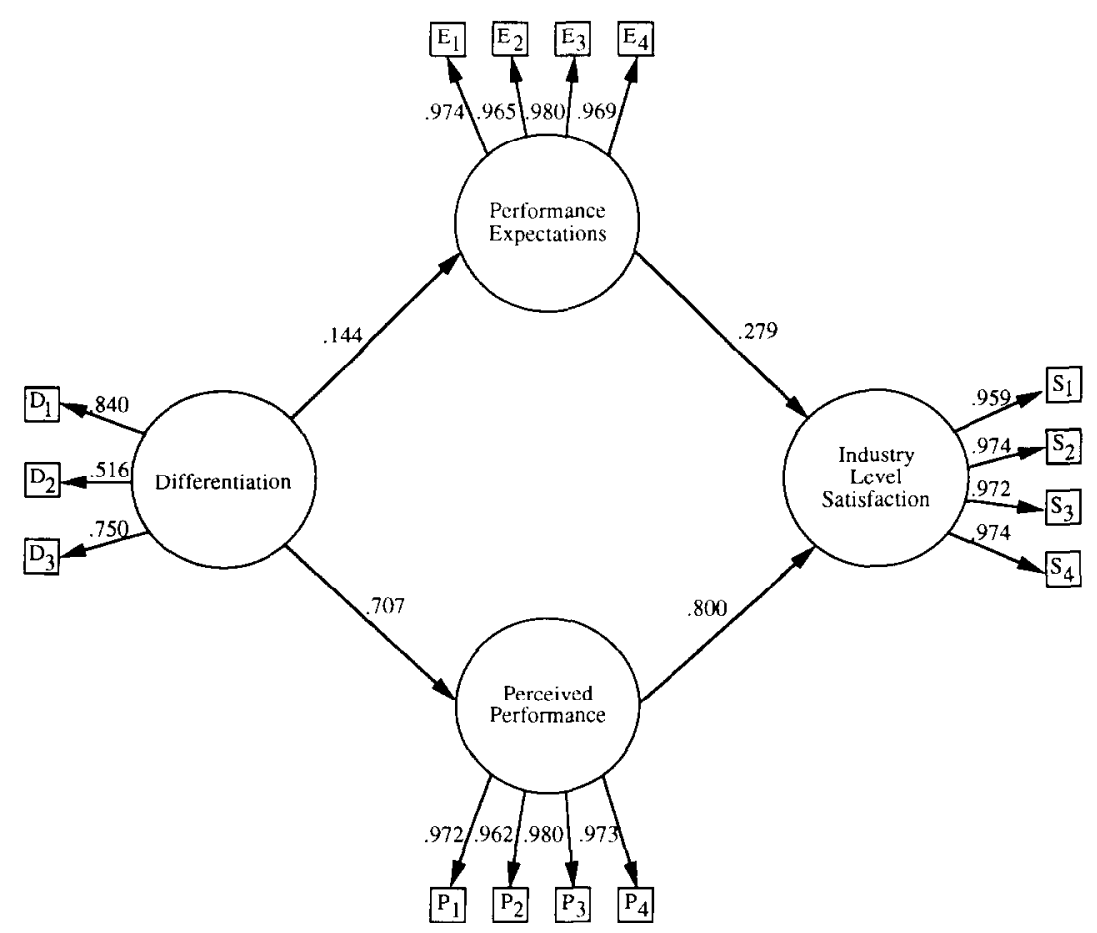

Fig. 2. Results. 
The results are presented in Fig. 2. The measurement loadings are all large and positive. Overall, the measurement model accounts for $93 \%$ of the available covariance in the measurement indicators. The structural model accounts for $83 \%$ of the latent variable covariance. Importantly, $87 \%$ of the variance in customer satisfaction across industries is accounted for. Tukey's jackknifing method was used to assess the precision of each estimate (Fornell and Barclay, 1993). Even though there are no statistical grounds on which to generalize the findings beyond the included 22 industries, the jackknifing results show that the variation in coefficients is quite small.

The results are very consistent with the proposition that differentiation increases perceived performance (coefficient of 0.707) which, in turn, increases satisfaction (coefficient of 0.800 ). Consistent with an economic model of rational expectations (Muth, 1961), aggregate industry expectations do covary with performance. The correlation between these latent variables is 0.349 . There is also a positive effect of differentiation on expectations (0.144). This is consistent with Wright's (1986) notion that customers have some intuitive understanding of marketers' actions. To some extent, customers understand that there are differences across industries with respect to the availability of options that meet particular customer needs.

Finally, expectations have some direct positive effect on satisfaction (0.279). This result supports Van Raaij's (1989) and Schelling's (1978) contention that aggregate expectations serve as an anchor that positively affects post-purchase attitudes. The effect is small relative to that of performance on satisfaction. The effect is also inconsistent with the disconfirmation model, often used to predict individual level satisfaction, in which an increase in expectations should decrease satisfaction (Yi, 1991).

\subsection{Evidence for monopoly benchmarking}

Recall that a number of monopolies in Sweden use the CSB as an industry level benchmark for improving quality. Simple linear models were estimated to examine the possible existence of satisfaction trends for the six monopolies in our study when compared to the eight competitive product industries and eight competitive service industries. Overall satisfaction does not vary significantly by year for either the competitive products (average satisfaction index of 67,66, 66, and 
67 for 1989 through 1992) or the competitive services (average index of 64, 63, 63 and 62 for 1989 through 1992). But there is a significant increase in satisfaction for the monopolies through 1991 (average index of 56, 58, 60, and 60 for 1989 through 1992).

\subsection{An index of industry differentiation}

One of the more interesting aspects of our study is that we were able to use three different measures to operationalize the latent differentiation of offerings across industries. Our results suggest that the number or concentration of firms, the ease with which customers judge product or service differences, and the product versus service nature of the industries all reflect latent differentiation. To illustrate, we standardized our three measures and used the measurement loadings in Fig. 2 to construct a weighted index of differentiation for the 22 industries in our sample, which is presented in Table 1.

Table 1

Differentiation index scores for Swedish industries

\begin{tabular}{lc}
\hline Industry & Differentiation index \\
\hline Automobiles & 1.816 \\
Clothing retailers & 0.821 \\
Oil (gas) stations & 0.801 \\
Computers (main frames) & 0.625 \\
Department stores & 0.614 \\
Grocery stores & 0.611 \\
Furniture retailers & 0.419 \\
Charter travel companies & 0.282 \\
Banking (public) & 0.266 \\
Computers (personal) & 0.182 \\
Banking (business) & 0.178 \\
Airlines & -0.214 \\
Insurance (auto) & -0.234 \\
Insurance (life) & -0.312 \\
Insurance (business) & -0.402 \\
TV broadcasting & -0.443 \\
Railroad & -0.587 \\
Postal service (business) & -0.698 \\
Postal service (public) & -0.784 \\
Telecommunications (business) & -0.978 \\
Police & -1.009 \\
Telecommunications (public) & -1.061 \\
\hline
\end{tabular}


According to this index, automobiles and public telecommunications are the most and least differentiated industries respectively. At more intermediate levels of differentiation are the banking industries, airlines, and insurance.

This differentiation construct varies systematically across industries and explains half the variance in aggregate perceptions of performance. Again, the model explains more than $87 \%$ of the variance in industry level satisfaction, supporting the argument that the observed differences in customer satisfaction have theoretical as well as empirical meaning.

\section{Discussion}

Overall our results suggest that more differentiated industries, those in which customers choose from among a variety of predictably different offerings, have systematically higher levels of aggregate perceived performance and subsequent aggregate satisfaction. Competitive product industries offer predictable variety and have high customer satisfaction. Competitive service industries are less differentiated and have more intermediate levels of satisfaction. According to our findings, service monopolies are the least differentiated and have the lowest satisfaction.

The results also demonstrate that aggregate expectations covary with perceived performance and have some positive effect on satisfaction. Because these expectations contain past performance information, they serve to anchor satisfaction in the direction of the expectations. The more customers, on the whole, expect from products and services, the greater their subsequent satisfaction. This finding is consistent with Katona's research as well as theorizing by Van Raaij (1989) and Schelling (1978).

Two potential limitations of our study deserve attention. One is that the results may be driven primarily by a qualitative difference between monopolies and non-monopolies. Certain monopolies may be so low in differentiation and perceived performance that they explain most of our results. A second model was estimated which included the competitive product and service industries only $(n=16)$ to explore this possibility. The results are very consistent with those in Fig. 2. Differentiation has a positive effect on perceived performance $(0.650)$ 
which, in turn, has a positive effect on satisfaction (0.814). Differentiation also has a positive effect on expectations $(0.318)$ which, in turn, has a positive effect on satisfaction (0.173). Thus our results do not simply reflect monopoly versus non-monopoly differences. One interesting difference was that the latent variable correlation between expectations and perceived performance was higher here than for the model that included monopolies $(0.660$ versus 0.349$)$. This suggests that aggregate expectations are more accurate among the more competitive industries.

A second potential limitation is that the low ratings for the service monopolies on the differentiation index (Table 1) may be driven disproportionately by $D_{1}$, the concentration measure. To examine this, we recomputed the index using the ease of judging quality $\left(D_{2}\right)$ and product versus service orientation $\left(D_{3}\right)$ measures only. The industry ratings on differentiation were quite consistent with those in Table 1 (correlation of 0.86 ), with one exception. The insurance industries dropped to a level on par with that of the monopolies. This is because the insurance industries have low aggregate ratings on $D_{2}$, the ease with which customers are able to judge quality differences.

The study demonstrates the value of the Swedish indices as benchmarks for evaluating and improving performance. Although speculative, it appears that the monopolies in Sweden are making use of these industry level benchmarks. But this research is only a beginning. There is much to be learned regarding intra- and inter-industry differences in customer satisfaction. This process is certain to involve the continued integration of economic and psychological perspectives (Van Raaij, 1981; Wärneryd, 1988). In conjunction with related research on job satisfaction and subjective well being, we hope that this research will provide a useful building block for the overall study of economic psychology.

\section{References}

Anderson, R.E., 1973. Consumer dissatisfaction: The effects of disconfirmed expectancy on perceived product performance. Journal of Marketing Research 10, 38-44.

Andreasen, A.R. and A. Best, 1977. Consumers complain - Does business respond? Harvard Business Review 55, 93-101.

Elster, J. and J.E. Roemer, 1991. Interpersonal Comparisons of Well-Being. Cambridge: Cambridge University Press. 
Fornell, C., 1992. A national customer satisfaction barometer: The Swedish experience. Journal of Marketing 56,6-21.

Fornell, C. and D.W. Barclay, 1993. Jackknifing in PLS. Research Note, The University of Michigan, School of Business Administration, Ann Arbor, MI, 48109, USA.

Fornell, C. and W.T. Robinson, 1983. Industrial concentration and consumer satisfaction/ dissatisfaction. Journal of Consumer Research 9, 403-412.

Grönroos, C., 1983, Strategic management and marketing in the service sector. Cambridge, MA: Marketing Science lnstitute.

Howard, J.A., 1977. Consumer Behavior: Application of Theory. New York: McGraw Hill.

Howard, J.A., 1989. Consumer Behavior in Marketing Strategy. Englewood Cliffs, NJ: PrenticeHall.

Hunt, H.K., 1988. 'Consumer satisfaction/dissatisfaction and the consumer interest'. In: E.S Maynes (Ed.), The Frontier of Research in the Consumer Interest (pp. 731-747). Columbia, MO: American Council on Consumer lnterests.

Johnson, M.D. and C. Fornell, 1991. A framework for comparing customer satisfaction across individuals and product categories. Journal of Economic Psychology 12, 267-286.

Jorgenson, D.W., 1990. Aggregate consumer behavior and the measurement of social welfare. Econometrica 58, 1007-1040.

Katona, G., 1975. Psychological Economics. New York: Elsevier.

Katona, G., 1980. Essays on Behavioral Economics. Ann Arbor, MI: The University of Michigan, Institute for Social Research.

Lachman, R., J.L. Lachman and E.C. Butterfield, 1979. Cognitive Psychology and Information Processing: An Introduction. Hillsdale, NJ: Erlbaum.

Muth, J.F., 1961. Rational expectations and the theory of price movements. Econometrica 29, 315-335.

Ölander, F., 1977a. Can consumer dissatisfaction and complaints guide public consumer policy. Journal of Consumer Policy 1, 124-137.

Ölander, F., 1977b. 'Consumer satisfaction - A skeptic's view'. In: H.K. Hunt (Ed.), Conceptualization and Measurement of Consumer Satisfaction and Dissatisfaction (pp. 409-452). Cambridge, MA: Marketing Science Institute.

Ölander, F., 1988. 'Consumer satisfaction/dissatisfaction and the consumer interest'. In: E.S. Maynes (Ed.), The Frontier of Research in the Consumer Interest (pp. 753-759). Columbia, MO: American Council on Consumer Interests.

Oliver, R.L., 1977. Effect of expectations and disconfirmation on post exposure product evaluations: An alternative interpretation. Journal of Applied Psychology 62, 480-486.

Oliver, R.L., 1980. A cognitive model of the antecedents and consequences of satisfaction decisions. Journal of Marketing Research 17, 460-469.

Pfaff, M., 1977. 'The index of consumer satisfaction: Measurement problems and opportunities'. In: H.K. Hunt (Ed.), Conceptualization and Measurement of Consumer Satisfaction and Dissatisfaction (pp. 36-71). Cambridge, MA: Marketing Science Institute.

Schelling, T.C., 1978. Micromotives and Macrobehavior. New York: Norton.

Sen, A., 1979. 'Interpersonal comparisons of welfare'. In: M.J. Boskin (Ed.), Economics and Human Welfare: Essays in Honor of Tibor Scitovsky (pp. 183-201). New York: Academic Press.

Simon, J.L., 1974. Interpersonal welfare comparisons can be made - and used for redistribution decisions. Kyklos 27, 63-98.

Tinbergen, J, 1991. On the measurement of welfare. Journal of Econometrics 50, 7-13.

Van Raaij, W.F., 1981. Economic psychology. Journal of Economic Psychology 1, 1-24.

Van Raaij, W.F., 1989. Economic news, expectations and macro-economic behavior. Journal of Economic Psychology 10, 473-493. 
Wärneryd, K.E., 1988. 'Economic psychology as a field of study'. In: W.F. van Raaij. G.M. van Veldhoven and K.E. Wärneryd, Handbook of Economic Psychology (pp. 2-41). Dordrecht: Kluwer.

Westbruok, R.A. and M.D. Reilly, 1983. Value-percept disparity: An alternative to the disconfirmation of expectations theory of consumer satisfaction. Advances in Consumer Research 10, $256-261$.

Wikström, S., 1983. Another look at consumer dissatisfaction as a measure of market performance. Journal of Consumer Policy 6, 19-35.

Wold, H., 1982. 'Systems under indirect observations using PLS'. In: C. Fornell (Ed.), A Second Generation of Multivariate Analysis: Methods (pp. 325-347). New York: Praeger.

Wold, H., 1989. Theoretical Empiricism. New York: Paragon House.

Wright, P., 1986. Schemer schema: Consumers intuitive theories about marketers' influence tactics. Advances in Consumer Research 13,1-3.

Yi, Y, 1991. 'A critical review of customer satisfaction'. In: V.A. Zeithaml (Ed.), Review of Marketing 1990. (pp. 68-123). Chicago, IL: American Marketing Association.

Zeithaml, V.A., L.L. Barry and A. Parasuraman, 1988. Communication and control processes in the delivery of scrvice quality. Journal of Marketing 52, 35-48. 